\title{
Degradação de revestimentos de argamassa com finos de resíduos de concreto por ciclos térmicos
}

\author{
Degradation of rendering mortars made with fine \\ concrete aggregates by thermal cycles
}

\section{J eferson Alcântara Alves Sentena Claudio de Souza Kazmierczak Laércio Antônio Krein}

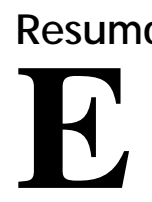

ste trabalho avalia propriedades de revestimentos de argamassa com finos de concreto submetidos a envelhecimento acelerado com ciclos térmicos, utilizando-se um método de ensaio baseado na NBR 15575-4 (ABNT, 2013). As argamassas foram produzidas no traço 1:1:6 em volume (cimento, cal e areia) utilizando-se cimento CP II F-32, cal CH-I em pasta, areia de rio e finos produzidos a partir de agregado reciclado de concreto, adicionado nos teores de 2\%; 4,5\%; 7\% e 9,5\% em relação à massa da areia. Os revestimentos foram aplicados sobre substrato de cerâmica vermelha e avaliados, aos 28 dias de idade, a partir da resistência de aderência e forma de ruptura (NBR 13528 (ABNT, 2010)), da dureza superficial determinada por durômetro Shore tipo D (ASTM D 2240-5 (AMERICAN..., 2005)) e da velocidade de propagação de ondas ultrassônicas. Após, os sistemas formados pelo revestimento de argamassa aplicado sobre o substrato cerâmico foram submetidos a envelhecimento acelerado por exposição à ciclagem térmica, o que degradou os revestimentos. Todos os revestimentos apresentaram queda de dureza superficial (na ordem de 10\%), diminuição da velocidade de propagação de ondas ultrassônicas (na ordem de 25\%) e queda de resistência dos valores médios de aderência, na ordem de 15\%. A forma de ruptura observada nos ensaios de resistência de aderência foi fortemente alterada em função do envelhecimento, sendo possível constatar que os revestimentos com $2 \%$ e $4,5 \%$ de finos apresentaram maior degradação.

Palavras-chave: Envelhecimento acelerado. Ciclos térmicos. Finos reciclados de concreto. Revestimento de argamassa.

\section{Abstract}

This study evaluates the loss of the properties of rendering mortars with recycled fine aggregate submitted to thermal cycling tests based on the NBR 15575-4 (ABNT, 2013) standard. The mortars were produced at a mix-proportion of 1:1:6 in volume (cement, lime and sand) using Brazilian cement CP II F-32, CH-I lime putty, river sand and fine aggregate produced from recycled concrete, in compositions with 2, 4.5, 7 and 9.5\% relatively to the mass of sand. The rendering mortars were applied on ceramic substrate and evaluated, at 28 days of age, for bond tensile strength (NBR 13528 (ABNT, 2010)), surface hardness determined by Shore durometer type D (ASTM D 2240-5 (AMERICAN..., 2005)) and the velocity of ultrasound waves. The systems formed by the rendering mortars applied on the ceramic substrate were subjected to accelerated ageing by exposure to thermal cycling, which degraded the mortars. All rendering mortars presented superficial hardness decline (in the order of 10\%), lowered velocity of ultrasound waves (about 25\%) and lowered bond tensile strength by about 15\%. The evaluation of the rupture of the rendering mortars showed that those with 2 e $4.5 \%$ fine aggregate content suffered the greater degradation.

Keywords: Accelerated ageing. Recycled fine aggregate. Rendering mortar. Thermal cycle. 


\section{Introdução}

Segundo o Ministério de Minas e Energia do Brasil (2016), no ano de 2008 a produção de areia chegou a 279 milhões de toneladas e estima-se que em 2030 possa chegar a valores entre 0,524 e 1,276 bilhões de toneladas, dependendo do cenário de crescimento utilizado. $\mathrm{O}$ aumento de consumo de agregados é consequência do crescimento da construção civil, e tem como resultados o esgotamento de fontes de recursos naturais não renováveis, e uma grande geração de resíduos resultantes dos diversos processos de produção do setor. Duas alternativas para amenizar o problema são a incorporação de resíduos gerados pelo setor na produção de materiais de construção civil e o aumento da durabilidade das obras civis. Entretanto, é necessário ressaltar que a incorporação de resíduos em materiais de construção civil, sem um estudo aprofundado de seu comportamento, pode resultar em diminuição da vida útil do componente. Para que se possa implementar processos de reciclagem, surge a necessidade da investigação do desempenho dos novos materiais, com foco na durabilidade.

A durabilidade dos revestimentos de fachada está relacionada à sua interação com fenômenos climáticos. Dentre os principais fatores de deterioração, destacam-se as variações de temperatura, que são o foco deste trabalho. As argamassas de revestimento estão sujeitas a dilatações com o aumento de temperatura e a contrações com a sua diminuição. A intensidade e a forma da variação dimensional vão depender da variação da temperatura e das propriedades térmicas dos materiais constituintes do revestimento, das características do substrato sobre a qual a argamassa está aplicada e de sua vinculação com o restante do edifício. A variação de temperatura a que o revestimento é sujeito ocorre em função de alterações de intensidade de exposição à radiação solar, que ocorrem ao longo do dia ou em função de mudanças de estações. Eventualmente, podem ocorrer mudanças bruscas de temperatura, como as decorrentes da chuva sobre uma fachada aquecida, no fenômeno conhecido como choque térmico, que gera fortes tensões internas na argamassa. A deterioração do revestimento também é decorrente de gradientes de temperatura entre diferentes regiões do sistema de fechamento vertical (revestimento e substrato, por exemplo), das diferentes propriedades térmicas dos materiais que compõem a fachada e do tipo de sistema de vedação utilizado.

Os processos de transferência de calor que ocorrem em um sistema de revestimento ao longo de um dia são ilustrados na Figura 1.

As diferenças de temperatura que ocorrem ao longo do tempo geram tensões internas nas argamassas, que resultam na formação gradual de microfissuras que, ao aumentarem em quantidade e dimensões, provocam a deterioração do revestimento e diminuição de sua vida útil.

As principais propriedades relacionadas à degradação da argamassa em função de gradientes de temperatura são o coeficiente de expansão térmica da argamassa e a sua condutividade térmica.

\section{Figura 1 - Processos de transferência de calor nos revestimentos}

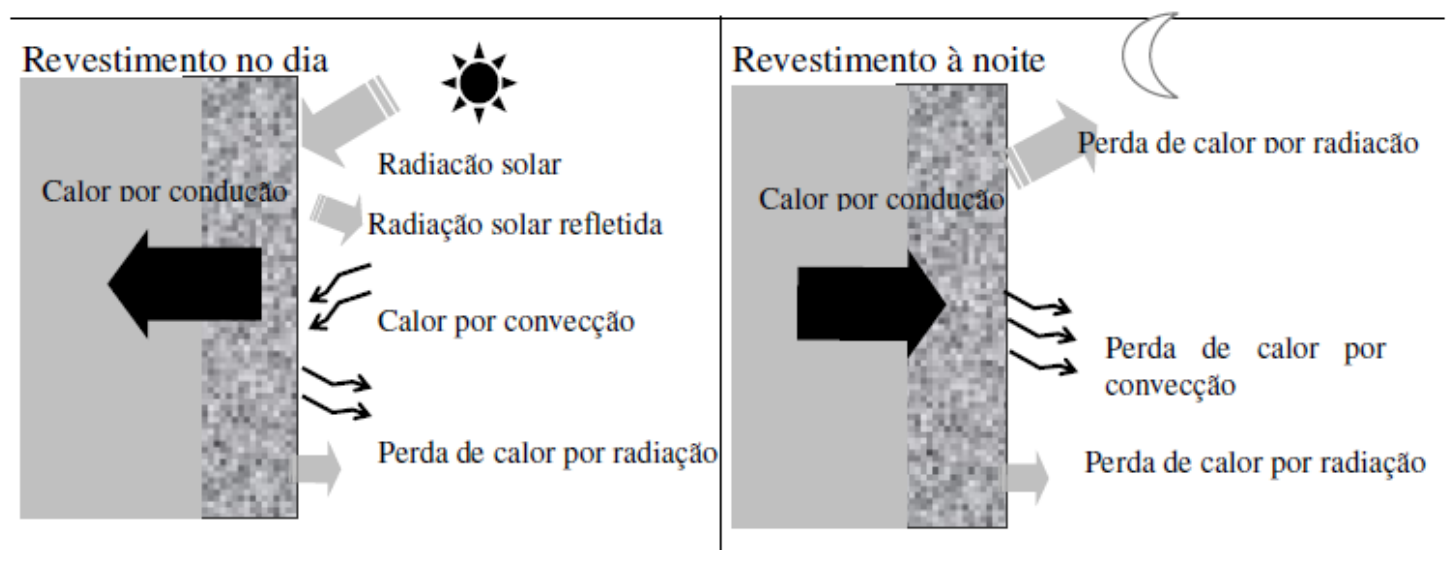

Fonte: Esquivel (2009). 
A variação volumétrica que um material apresenta em função de um gradiente de temperatura usualmente é expressa por seu coeficiente de expansão térmica (CET). O CET de uma argamassa é dependente dos seus materiais constituintes, do teor de umidade e do volume de vazios.

Segundo Schulson, Swainson e Holden (2001), o CET é um parâmetro fundamental para determinar a tensão interna entre as diferentes fases em materiais à base de cimento e possibilita prever possíveis danos induzidos pelas diferentes dilatações térmicas de cada fase. Os valores de CET em pastas de cimento são dependentes do tipo de cimento utilizado e da relação água/cimento (MARUYAMA; TERAMOTO; IGARASHI, 2014). Como a pasta é composta por diversos produtos de hidratação, Schulson, Swainson e Holden (2001) afirmam que a movimentação térmica diferencial entre compostos, como o hidróxido de cálcio (C-H) e o silicato de cálcio hidratado (C-S-H, cujo CET é menor que o do C$\mathrm{H})$, gera tensões no interior de pasta submetida a gradientes de temperatura. Segundo Shui et al. (2010), a substituição de clínquer por adições pozolânicas diminui o CET, em função das pozolanas diminuírem a porosidade da pasta e consumirem C-H. Em argamassas, além das diferenças de CET entre os produtos de hidratação, soma-se a variação em relação ao agregado. Valores típicos para CET de pasta de cimento em estado endurecido são de 15 a 20 x $10^{-6} /{ }^{\circ} \mathrm{C}$ (MEYERS, 1940), e em agregados variam de 5 a $12 \times 10^{-6} /{ }^{\circ} \mathrm{C}$ (GHABEZLOO, 2011). As diferenças de CET entre os materiais constituintes da argamassa proporcionam tensões internas sempre que houver variação de temperatura na argamassa, resultando, ao longo do tempo, na formação de microfissuras. Em situações específicas, como no caso de aquecimento ou resfriamento súbito de uma argamassa, o processo de geração de fissuras é imediato, e pode se manifestar em nível de micro ou macroestrutura do material (SHUI et al., 2010).

Além dos materiais constituintes, Zeng et al. (2012) afirmam que a porosidade e o teor de ar incorporado em uma argamassa exercem efeito significativo sobre a deformação térmica, e o CET diminui com o aumento da porosidade. O CET também é influenciado pelo teor de umidade da argamassa (variando cerca de $10 \%$ entre um material seco ou saturado), uma vez que o CET da água é superior ao dos constituintes da argamassa, gerando tensões elevadas na rede de poros da argamassa quando ocorrem gradientes de temperatura.

Um segundo fator que rege a deformação térmica da argamassa é a sua condutividade térmica. Ela define a velocidade do fluxo de calor, e pode diminuir ou aumentar as tensões térmicas na argamassa. Kim et al. (2003), estudando concreto, argamassa e pasta de cimento, identificaram sete fatores que afetam a condutividade térmica: idade, volume de agregado, quantidade de cimento, tipos de aditivos, fração de finos dos agregados, temperatura e umidade da amostra. Segundo eles, o volume de agregados e a umidade da amostra são os principais fatores que alteram a condutividade de materiais à base de cimento. Esta opinião é corroborada por Gomes et al. (2017), que afirmam que a condutividade térmica é fortemente influenciada pelo teor de umidade.

Além das tensões térmicas existentes na argamassa, os revestimentos também são sujeitos a tensões diferenciais decorrentes da interação entre a camada de argamassa e os demais materiais que compõem o sistema de fechamento vertical (como o substrato ou os sistemas de proteção superficial). Em estudo realizado por Saraiva, Bauer e Bezerra (2011), sobre descolamentos de revestimentos cerâmicos em fachadas, foi constatada a existência de tensões na interface entre a argamassa colante e as placas cerâmicas em decorrência de esforços de origem térmica, e um aumento de tensões em torno de $60 \%$ nas placas cerâmicas com maior coeficiente de absorção térmica, uma vez que estas aumentam mais sua temperatura e sofrem maiores dilatações. Segundo os autores, a camada de acabamento submetida a tensões térmicas sofre alteração volumétrica, o que gera tensões diferenciais em relação às camadas inferiores do revestimento.

Diversos autores buscam determinar a influência das variações de temperatura nos revestimentos com argamassa e em sua durabilidade a partir de ensaios acelerados, como Guimarães et al. (2002); Ballester et al. (2009) e Saraiva, Bauer e Bezerra (2011). Segundo Freitas et al. (2008), em um trabalho que discute a avaliação da durabilidade de revestimentos de argamassa com base em normas europeias, a variação de temperatura, a variação da umidade relativa, a incidência de radiação solar e as precipitações são os agentes de degradação de maior importância, sendo fundamentais em ensaios acelerados de envelhecimento. Os principais requisitos a serem avaliados, em diferentes momentos durante o ensaio de envelhecimento acelerado do revestimento, são o coeficiente de absorção de água por capilaridade, a permeabilidade à água, a adesão ao substrato e características da superfície do revestimento, como o nível de fissuração e as diferenças de coloração.

Miranda e Selmo (2005) submeteram revestimentos de argamassa com incorporação agregados miúdos provenientes da reciclagem de resíduos de construção civil a 10 ciclos térmicos de aquecimento e choque térmico por umedecimento utilizando o método IPT (INSTITUTO..., 1998) - 
semelhante ao adotado posteriormente na NBR 15575-4 (ABNT, 2013) - e observaram microfissuração em quase todos os revestimentos, e fissuração visível somente nas argamassas com elevado teor de partículas finas em sua constituição. Não foi constatada perda de resistência de aderência. Esquivel (2009) submeteu argamassas à base de cimento a 30 ciclos térmicos em ensaio semelhante ao estabelecido pela NBR 15575-4 (ABNT, 2013), e concluiu que cinco propriedades influenciam o comportamento dessas argamassas frente ao choque térmico: resistência mecânica, módulo de elasticidade, coeficiente de Poisson, coeficiente de expansão térmica e condutividade térmica. O ensaio promoveu a diminuição na resistência de aderência em todas as combinações, e houve alteração na forma de ruptura das argamassas de revestimento após o envelhecimento acelerado, com aumento da taxa de rupturas adesivas.

A partir de 2014, com a entrada em vigor da Norma de Desempenho NBR 15575 (ABNT, 2013), o Brasil começou a contar com um método de envelhecimento acelerado por ciclagem térmica normalizado, descrito na seção 4 da referida norma. A norma é aplicável a sistemas de vedação verticais, nos quais se enquadram os sistemas de alvenaria revestida com argamassa. A norma cita requisitos relacionados aos sistemas de vedação verticais, como: funcionalidade, segurança estrutural, estanqueidade, desempenho térmico, desempenho acústico, durabilidade e manutenibilidade. No tocante à durabilidade, é proposto um método de ensaio acelerado que simula os efeitos da variação térmica e exposição à chuva a que o revestimento estará submetido ao longo da sua vida útil, que deve ser utilizado para se definir a aceitação ou não de sistemas de vedação verticais em edifícios. A norma especifica como parâmetros de avaliação da degradação do sistema submetido ao envelhecimento acelerado por ciclagem térmica o "[...] aparecimento de fissuras, trincas, deslocamentos ou outras deteriorações em ambas as faces do corpo-de-prova [...]", e a “[...] avaliação do deslocamento horizontal após $45 \mathrm{~min}$ de estabilização da temperatura superficial em $(80 \pm 3$ ${ }^{\circ} \mathrm{C}$ ) e imediatamente após o resfriamento [...]”, ao longo de 10 ciclos de ensaio. A ocorrência de fissuras (que ocorrem sempre que as tensões provenientes da contração volumétrica por diminuição da temperatura superam a resistência à tração da argamassa) ou de algum dos demais sintomas de degradação citados é suficiente para que o sistema seja reprovado no requisito durabilidade. Entretanto, esses parâmetros não fornecem informações sobre as alterações de microestrutura que podem estar ocorrendo ao longo do processo de envelhecimento a que a amostra está sendo submetida, o que geralmente impossibilita uma análise quantitativa da diferença de desempenho entre diversos sistemas de revestimento.

Verifica-se ainda que os estudos relacionados com o envelhecimento acelerado de revestimentos, com raras exceções, não contemplam o uso de argamassas de revestimento com resíduos. Além disto, há necessidade de adoção de outros critérios, além dos especificados na norma brasileira, que permitam a avaliação da degradação de revestimentos de argamassa expostos a ensaios de envelhecimento acelerado por gradientes térmicos, visto que apenas a avaliação da fissuração superficial e a análise de deformações não são suficientes para distinguir o nível de degradação em muitos sistemas de revestimento.

\section{Programa experimental}

Foram elaboradas argamassas no traço 1:1:6 (cimento : cal em pasta : areia natural de rio), ao qual foram adicionados quatro teores de finos ( $2 \%$; 4,5\%; 7\% e 9,5\%). O agregado fino foi obtido pela moagem de concreto, sendo utilizada apenas a fração passante na peneira $0,075 \mathrm{~mm}$. As quatro argamassas foram caracterizadas em seu estado fresco e endurecido, e utilizadas como revestimento sobre um substrato de cerâmica vermelha. Após cura por 28 dias, foi determinada a resistência de aderência por tração direta e a existência de fissuras nos revestimentos, a dureza superficial e a velocidade de propagação de ondas ultrassônicas. Na sequência, os sistemas (substrato + argamassa) foram submetidos a envelhecimento acelerado, após o qual os ensaios foram repetidos de forma a permitir a análise da degradação do revestimento.

\section{Materiais}

Os aglomerantes utilizados na confecção das argamassas foram o cimento Portland CP II-F-32, com massa específica $2,91 \mathrm{~g} / \mathrm{cm}^{3}$ e cal hidratada $\mathrm{CH}$ I, com massa específica 2,40. Foi adotado como agregado uma areia natural de rio da região de Porto Alegre, RS, de origem quartzosa, com massa específica $2,54 \mathrm{~g} / \mathrm{cm}^{3}$ e massa unitária no estado solto $1,55 \mathrm{~g} / \mathrm{cm}^{3}$, utilizando-se os grãos passantes na peneira $4,8 \mathrm{~mm}$, lavados em água corrente até a ausência de finos passantes na peneira 0,075 mm. A esses materiais foram adicionados finos procedentes da britagem de concreto, em quatro proporções. Os finos são provenientes da cominuição de elementos pré-fabricados de concreto curados sob cura térmica a vapor, com resistência de 37,0 $\mathrm{MPa}$, fornecidos por uma empresa de pré-moldados. Os resíduos de concreto 
foram beneficiados em moinhos de mandíbulas e posteriormente de bolas, e separados de modo a apresentarem apenas material passante na peneira $0,075 \mathrm{~mm}$. A massa específica do fino de ARC (Agregado Reciclado de Concreto) foi determinada conforme a NBR NM 23 (ABNT, 2000), resultando em $2,37 \mathrm{~g} / \mathrm{cm}^{3}$.

A distribuição granulométrica da areia pode ser visualizada na Tabela 1. A distribuição granulométrica dos finos provenientes da cominuição do concreto e dos aglomerantes utilizados foi determinada por um granulômetro laser Microtrac S3500, utilizando-se álcool isopropílico como dispersante, e pode ser visualizada na Tabela 2.

A compacidade das quatro misturas de materiais, no estado seco, foi determinada segundo a NBR NM 45 (ABNT, 2006). Os resultados constam na Tabela 3.

Para o substrato, foram utilizados blocos cerâmicos nas dimensões de 140 mm x190 mm x 290 mm, com resistência à compressão característica de 12,94 MPa e índice de absorção de água de 11,67 g/193,55 $\mathrm{cm}^{2} / \mathrm{min}$.

\section{Método}

As argamassas de revestimento foram produzidas no traço em volume em cimento, cal em pasta e areia, 1:1:6, com adição de finos em percentual sobre a massa da areia, utilizando-se uma argamassadeira de eixo vertical. $\mathrm{O}$ traço em massa correspondente ao teor de finos de $2 \%$ é 1 (cimento) : 1,153 (cal em pasta) : 9,298 (areia lavada, sem finos) : 0,186 (finos), com $\mathrm{a} / \mathrm{c}=1,737$ (incluindo a água da cal em pasta). A quantidade de água da argamassa com $2 \%$ de finos foi ajustada para a consistência por espalhamento de $260 \pm 5 \mathrm{~mm}$. Os demais traços mantiveram o teor de água fixo e a trabalhabilidade foi ajustada com aditivo à base de policarboxilato. As argamassas foram moldadas em sala climatizada com temperatura de $23 \pm 2-{ }^{\circ} \mathrm{C}$ e umidade de $60 \pm 10 \%$. Para cada mistura foram realizadas pelo menos três repetições de cada ensaio. Na Figura 2 é visualizada a composição quantitativa das argamassas utilizadas, no estado fresco.

Todas as argamassas foram desmoldadas 24 h após a mistura e permaneceram em ambiente de laboratório na condição de temperatura de $23 \pm 2{ }^{\circ} \mathrm{C}$ e umidade relativa de $60 \pm 10 \%$. Foi determinada a trabalhabilidade das argamassas no estado fresco e, após 28 dias de cura, foram determinadas as resistências a compressão e a flexão em prisma, densidade de massa, módulo de elasticidade dinâmico, índice de vazios e coeficiente de capilaridade, a partir da média de três valores. A porosidade total das argamassas no estado endurecido foi determinada a partir de ensaios com um porosímetro a mercúrio PoreMaster 33, adotando-se uma pressão máxima de intrusão de 227,37 MPa e ângulo de contato de $140^{\circ}$.

\section{Tabela 1 - Composição granulométrica do agregado miúdo}

\begin{tabular}{c|c|c}
\hline Peneira (mm) & Retido (\%) & Retido Acumulado (\%) \\
\hline 2,4 & 17,9 & 17,9 \\
1,2 & 18,3 & 36,2 \\
0,6 & 15,5 & 51,7 \\
0,3 & 17,3 & 68,9 \\
0,15 & 15,5 & 84,5 \\
Fundo & 15,5 & 100,0 \\
\hline Módulo de finura & $\mathbf{2 , 5 9}$ \\
\hline
\end{tabular}

Tabela 2 - Caracterização granulométrica dos aglomerantes e dos finos de concreto

\begin{tabular}{c|c|c|c}
\hline $\begin{array}{c}\text { \% de grãos passantes } \mathbf{x} \\
\text { tamanho máximo do grão }(\boldsymbol{\mu m})\end{array}$ & D $\mathbf{1 0}$ & D $\mathbf{5 0}$ & $\mathbf{D} \mathbf{9 0}$ \\
\hline Cal CH-I & 2,87 & 18,97 & 50,55 \\
Cimento CP II F-32 & 7,88 & 22,06 & 49,10 \\
Finos de concreto & 11,11 & 30,87 & 52,81 \\
\hline
\end{tabular}


Tabela 3 - Compacidade do material seco com diferentes teores de adição de finos de concreto

\begin{tabular}{c|c|c|c|c|c}
\hline Fino (\%) & $\mathbf{0}$ & $\mathbf{2}$ & $\mathbf{4 , 5}$ & $\mathbf{7}$ & $\mathbf{9 , 5}$ \\
\hline $\begin{array}{c}\left.\text { Massa unitária (g/cm }{ }^{3}\right) \\
\text { / desvio padrão }\end{array}$ & 1,843 & $1,846(0,004)$ & $1,847(0,003)$ & $1,850(0,003)$ & $1,837(0,005)$ \\
\hline
\end{tabular}

Figura 2 - Distribuição de percentual de volume dos materiais que compõem as argamassas no estado fresco

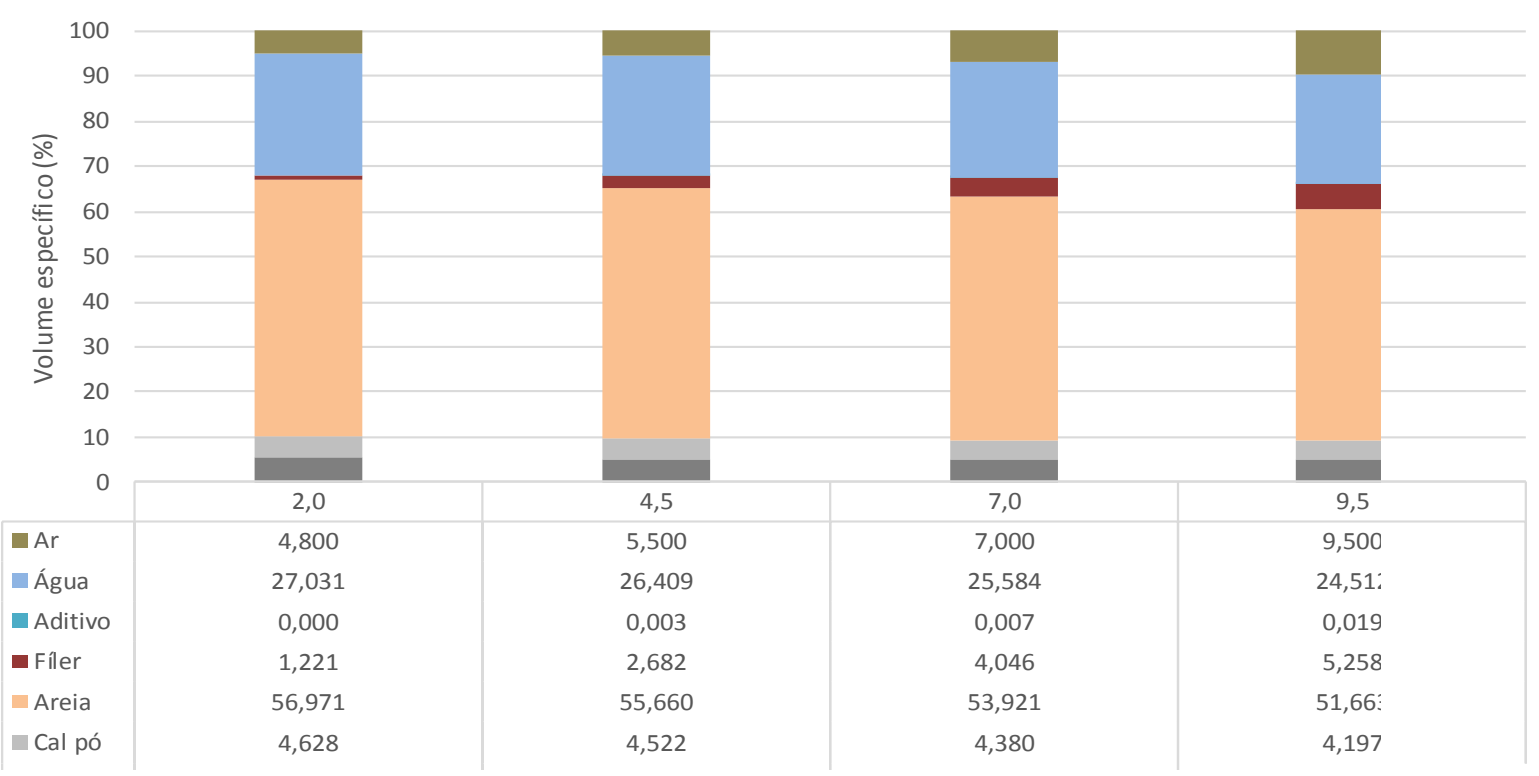

Para a avaliação dos revestimentos, substratos de cerâmica vermelha foram chapiscados e revestidos com as argamassas. A argamassa de chapisco foi produzida no traço 1:3, em volume, e aplicada de forma manual sobre a superfície dos blocos. Após $72 \mathrm{~h}$ de cura, foi realizado o revestimento, com uma espessura de $20 \pm 2 \mathrm{~mm}$. Após 28 dias de cura, nas mesmas condições especificadas para as argamassas, parte dos revestimentos foram avaliados com relação à existência de fissuras e determinadas a resistência de aderência a tração e a forma de ruptura (conforme especificações da NBR 13528 (ABNT, 2010)), a dureza superficial por durômetro Shore tipo D (ASTM D 2240-5 (AMERICAN..., 2005)) e a velocidade de propagação de ondas ultrassônicas com um aparelho Proceq - Pundit $\mathrm{Lab}^{+}$. Os demais, destinados aos ensaios de envelhecimento acelerado, após a cura, foram estocados em ambiente com temperatura de $60 \pm 5{ }^{\circ} \mathrm{C}$, até atingirem constância de massa. Na sequência, foram submetidos a ciclos de acréscimo de temperatura seguidos por resfriamento brusco por aspersão de água, conforme procedimento especificado na norma ABNT NBR 15575-4 (2013), alterando-se, entretanto, o tempo de ensaio para 40 ciclos. Para a ciclagem dos revestimentos, foram utilizadas câmaras de ensaio de dimensões 50 cm x $40 \mathrm{~cm}$ x $140 \mathrm{~cm}$, dotadas de um sistema de controle de temperatura programável. A eficiência do sistema foi aferida com o uso de uma câmara de filmagem em infravermelho e monitoração por termopares. O gráfico da Figura 3 demonstra ciclos de aquecimento e resfriamento típicos obtidos com o equipamento. Foram adotados uma temperatura mínima de $20 \pm 5{ }^{\circ} \mathrm{C}$ e máxima no patamar de $85 \pm 3$ ${ }^{\circ} \mathrm{C}$, o que atende o requisito da norma brasileira de desempenho e é coerente com o especificado por outros autores (CARÉ, 2008; JANOTKA; NÜRBERGEROVÁ, 2005; ZENG et al., 2012; SHUI et al., 2010). Com o tempo de aquecimento de $60 \mathrm{~min}$, um patamar de 60 min e um resfriamento de aproximadamente $60 \mathrm{~min}$, cada ciclo tem uma duração aproximada de $180 \mathrm{~min}$. O resfriamento ocorre com auxílio de aspersão de um jato contínuo de água sobre os revestimentos.

Os revestimentos foram avaliados aos 28 dias de idade e depois da exposição aos ciclos de envelhecimento acelerado, utilizando-se os seguintes métodos:

(a) propagação de ondas por ultrassom: o ensaio foi realizado obtendo-se a média de 20 leituras da velocidade de pulso em cada uma das amostras de 
cada traço de argamassa. A velocidade de propagação de ondas ultrassônicas é proporcional à porosidade do revestimento (SOLTANI et al., 2013), que pode ser aumentada em função do aparecimento de microfissuras;

(b) dureza superficial: a estimativa da dureza superficial dos revestimentos foi realizada com um durômetro Shore, conforme o método proposto por Lino (2013), a partir da média de 12 leituras; e

(c) resistência de aderência à tração: os valores de resistência de aderência foram obtidos pela média entre 18 arrancamentos. Como a resistência de aderência é influenciada por diversos fatores, como as características da argamassa, do substrato e as condições de aplicação do revestimento, é comum que ocorra uma elevada dispersão de resultados, que segundo Carasek (2012) varia entre $10 \%$ e $60 \%$. A autora considera aceitáveis ensaios cujo coeficiente de variação seja igual ou inferior a $25 \%$. Essa elevada variação dos resultados muitas vezes impede uma análise conclusiva sobre o comportamento do revestimento. Neste trabalho foram considerados espúrios os valores compreendidos fora do intervalo entre a média menos um desvio e a média mais um desvio padrão. A forma de ruptura em cada ensaio de arrancamento foi determinada utilizando-se o software de mapeamento ArcGis.

\section{Apresentação, análise e discussão dos resultados}

A primeira avaliação do efeito da adição dos diferentes teores de finos de concreto foi realizada determinando-se a alteração na compacidade da mistura de materiais que compõem a argamassa, no estado seco, em função dessa adição. Constata-se, a partir dos resultados da Tabela 3, que o acréscimo de finos até o teor de $7 \%$ proporciona maior compacidade para os materiais utilizados na argamassa, e que a partir desse ponto o excesso de finos exerce efeito de separação entre os grãos do agregado e perda de trabalhabilidade (observada pela necessidade de aumento no teor de aditivo plastificante - Figura 2). À medida que se adicionam maiores teores de finos há aumento do volume de pasta nas argamassas, assim como aumento no teor de ar incorporado (visualizados na Figura 2).

Os resultados dos ensaios de caracterização das argamassas no estado endurecido se encontram na Tabela 4.

A resistência à tração na flexão, a resistência à compressão, o módulo de elasticidade dinâmico e a densidade das argamassas diminuíram proporcionalmente ao acréscimo de adição de finos. A diminuição de propriedades mecânicas das argamassas se justifica principalmente pelo aumento no volume de vazios, que pode ser visualizada na Tabela 5.

Observa-se um acréscimo de porosidade à medida que se aumenta o teor de finos, com ênfase na faixa de poros entre $0,05 \mu \mathrm{m}$ e $5 \mu \mathrm{m}$, que corresponde aos poros capilares. O aumento da porosidade total indica, em teoria, maior capacidade de deformação da argamassa, à medida que se aumenta o teor de finos.

\section{Figura 3 - Ciclo de aquecimento e resfriamento típico obtido nas superfícies dos revestimentos e na interface revestimento/cerâmica durante o ensaio de envelhecimento acelerado}

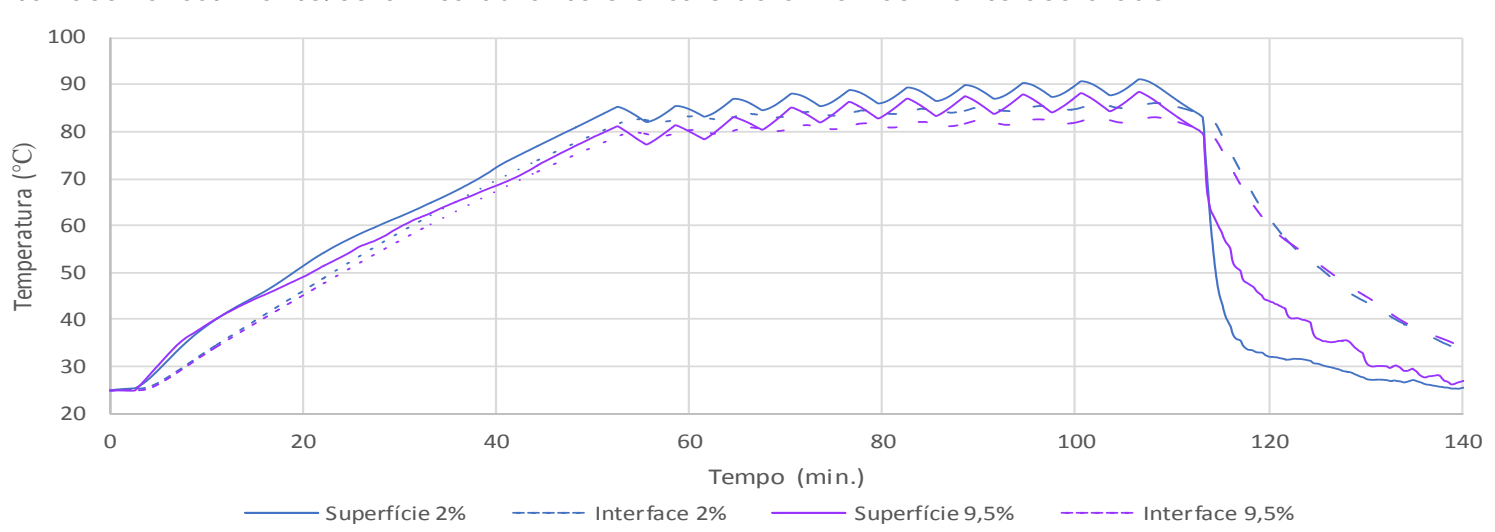


Tabela 4 - Características das argamassas no estado endurecido

\begin{tabular}{|c|c|c|c|c|c|c|c|}
\hline $\begin{array}{c}\text { Teor de } \\
\text { finos } \\
(\%)\end{array}$ & $\begin{array}{c}\text { Tração na } \\
\text { flexão } \\
\text { (MPa) } \\
\text { NBR } \\
13279 \\
\text { (ABNT, } \\
\text { 2005a) }\end{array}$ & $\begin{array}{c}\text { Resistência à } \\
\text { compressão } \\
\text { (MPa) NBR } \\
13279 \\
(\mathrm{ABNT} \\
2005 a)\end{array}$ & $\begin{array}{c}\text { Densidade } \\
\text { de massa } \\
\text { aparente } \\
\left(\mathbf{k g} / \mathbf{m}^{3}\right) \\
\text { NBR 13280 } \\
\text { (ABNT, } \\
2005 b)\end{array}$ & $\begin{array}{c}\text { Massa } \\
\text { específica } \\
\left(\mathrm{g} / \mathrm{cm}^{3}\right) \\
\text { NBR } \\
9778 \\
\text { (ABNT, } \\
2005 c)\end{array}$ & $\begin{array}{c}\text { Módulo de } \\
\text { elasticidade } \\
\text { dinâmico } \\
\text { (GPa) NBR } \\
15630 \\
\text { (ABNT, } \\
2009 \text { ) }\end{array}$ & $\begin{array}{c}\text { Coeficiente de } \\
\text { capilaridade } \\
\left(\mathrm{g} / \mathbf{d m}^{2} \cdot \mathrm{min}^{1 / 2}\right) \\
\text { NBR 15259 } \\
\text { (ABNT, 2005d) }\end{array}$ & 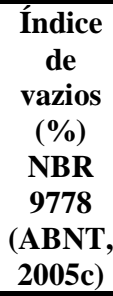 \\
\hline 2 & 2,407 & 7,540 & 1915 & 2,46 & 14,571 & 0,437 & 23,87 \\
\hline 4,5 & 2,402 & 7,467 & 1881 & 2,40 & 13,687 & 0,376 & 24,99 \\
\hline 7 & 2,355 & 7,481 & 1864 & 2,41 & 13,731 & 0,323 & 25,46 \\
\hline 9,5 & 2,297 & 6,981 & 1864 & 2,38 & 12,960 & 0,313 & 26,52 \\
\hline
\end{tabular}

Tabela 5 - Distribuição do volume de mercúrio intrudido nas amostras de argamassas no estado endurecido

\begin{tabular}{c|c|c|c|c}
\hline Finos (\%) & $\mathbf{2}$ & $\mathbf{4 , 5}$ & $\mathbf{7}$ & $\mathbf{9 , 5}$ \\
\hline $\boldsymbol{\varnothing}$ Poro $(\boldsymbol{\mu m})$ & \multicolumn{3}{|c}{ Volume de mercúrio $\left(\mathbf{c m}^{\mathbf{3}} / \mathbf{g}\right)$} \\
\hline$<0,05$ & 0,0176 & 0,0128 & 0,0104 & 0,0122 \\
$0,05 \leq \emptyset<5$ & 0,0867 & 0,0991 & 0,1058 & 0,1131 \\
$\geq 5$ & 0,0005 & 0,0126 & 0,0091 & 0,0078 \\
Volume total & 0,1048 & 0,1245 & 0,1253 & 0,1331 \\
\hline
\end{tabular}

O aumento no teor de finos também resulta em aumento de volume de pasta nas argamassas, e consequente diminuição no volume de agregado, o que diminui a condutividade térmica da argamassa, e consequentemente gera menores tensões diferenciais em função de ciclos térmicos, segundo Kim et al. (2003).

Os revestimentos de argamassa foram avaliados durante a sua cura, aos 28 dias de idade e após os ciclos de envelhecimento acelerado. Durante a cura, nenhum revestimento de argamassa apresentou fissuras visíveis, assim como após o procedimento de envelhecimento acelerado. Os demais resultados de avaliação dos revestimentos são discutidos a seguir.

A Figura 4 permite visualizar a diminuição da velocidade de propagação de onda ultrassônica entre os revestimentos após o envelhecimento acelerado, na ordem de $25 \%$, o que indica aumento na quantidade de vazios nas argamassas, resultante do processo de degradação dos revestimentos. O método não foi capaz de diferenciar os traços utilizados entre si.

Na Figura 5 são observados os resultados da avaliação de dureza superficial por meio de durômetro Shore tipo D.

Os valores de dureza superficial Shore indicam perda de dureza superficial, entre $7 \%$ e $13 \%$, em função do envelhecimento acelerado por ciclagens térmicas. Entretanto, o método também não permite a distinção do comportamento entre os diversos teores de adição de resíduo.

A perda de dureza na argamassa é consequência da degradação ocorrida no revestimento ao longo dos ciclos térmicos, que é comprovada a partir da análise da forma de ruptura da argamassa nos ensaios de resistência de aderência, discutida a seguir. O comportamento também é coerente com o aumento do volume de poros da argamassa, identificado a partir dos ensaios de ultrassom.

Os valores de resistência de aderência à tração dos revestimentos, discriminados em função do teor de finos incorporado na argamassa, são visualizados na Tabela 6 e na Figura 6.

Considerando-se todos os ensaios, o envelhecimento acelerado gerou uma queda média de 15\% na resistência de aderência dos revestimentos de argamassa (Tabela 7), o que é coerente com os resultados encontrados nos demais métodos de ensaio. Aparentemente, há maior queda das resistências de aderência dos revestimentos com maior teor de adição, na ordem de $30 \%$ para a argamassa com $7 \%$ de finos e de $39 \%$ para a argamassa com 9,5\% de finos. Entretanto, esses valores apresentam uma dispersão elevada, com coeficientes de variação na ordem de $0,3 \mathrm{MPa}$, o que resulta na impossibilidade de se distinguir estatisticamente os dois grupos (antes e depois do envelhecimento acelerado), e as diferenças em função do teor de finos das argamassas. 
Figura 4 - Velocidade de pulso da onda ultrassônica nos revestimentos

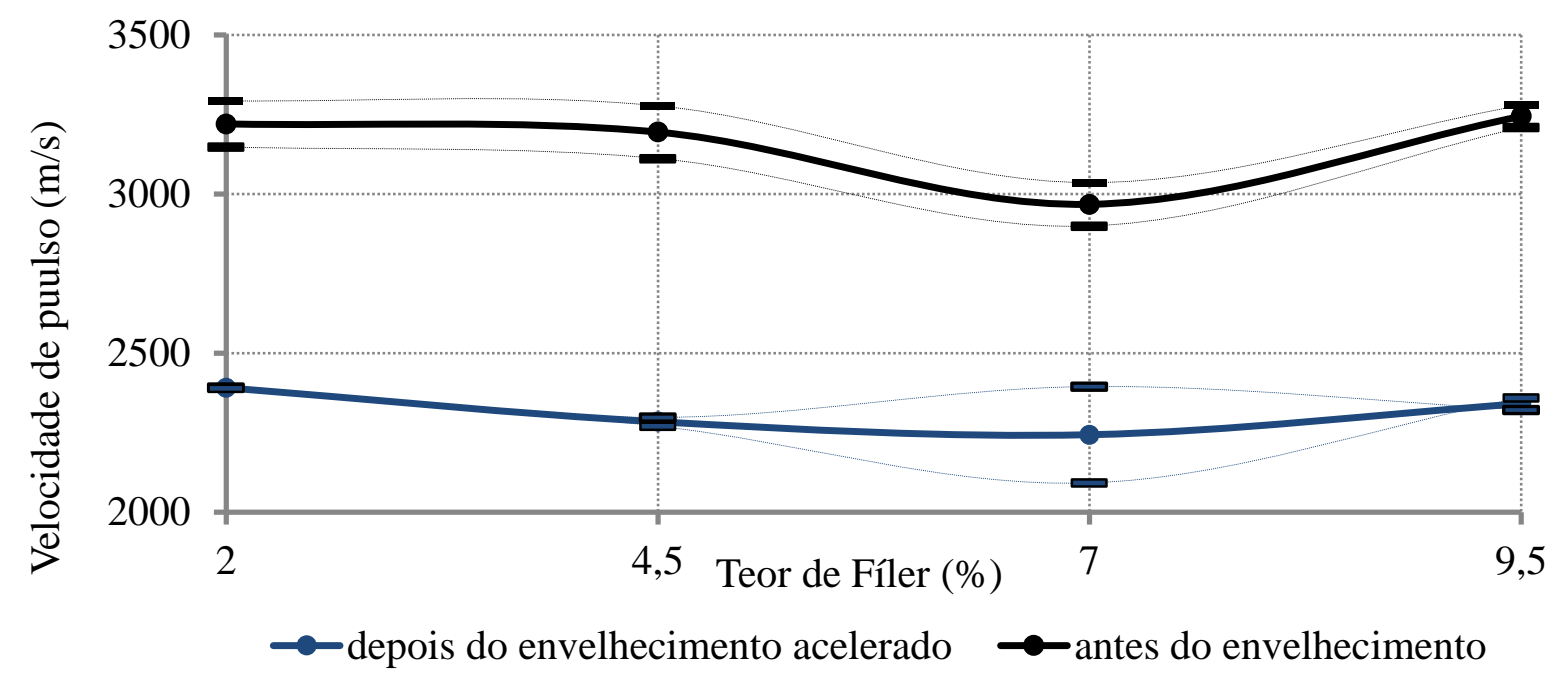

Figura 5 - Dureza superficial medida pelo índice Shore D

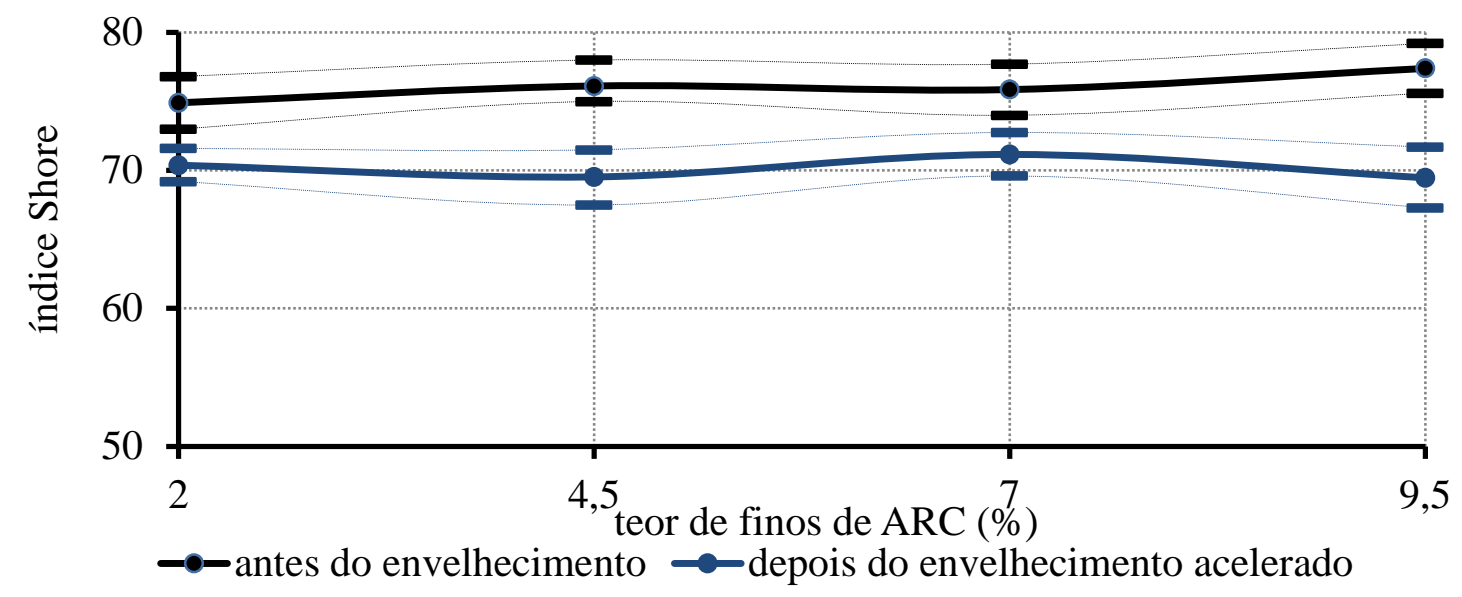

Tabela 6 - Médias das resistências de aderência à tração

\begin{tabular}{c|c|c|c|c|c|c}
\hline \multirow{2}{*}{$\begin{array}{c}\text { Finos } \\
(\%)\end{array}$} & \multicolumn{2}{|c|}{ Antes do envelhecimento acelerado } & \multicolumn{3}{c}{ Após envelhecimento acelerado } \\
\cline { 2 - 7 } & $\begin{array}{c}\text { Número } \\
\text { de leituras }\end{array}$ & $\begin{array}{c}\text { Resistência de } \\
\text { aderência } \\
\text { média (MPa) }\end{array}$ & $\begin{array}{c}\text { Desvio } \\
\text { padrão }\end{array}$ & $\begin{array}{c}\text { Número } \\
\text { de } \\
\text { leituras }\end{array}$ & $\begin{array}{c}\text { Resistência } \\
\text { de aderência } \\
\text { média (MPa) }\end{array}$ & $\begin{array}{c}\text { Desvio } \\
\text { padrão }\end{array}$ \\
\hline 2,0 & 12 & 0,88 & 0,17 & 12 & 0,93 & 0,27 \\
4,5 & 12 & 0,94 & 0,32 & 13 & 0,92 & 0,27 \\
7,0 & 13 & 0,77 & 0,30 & 11 & 0,54 & 0,26 \\
9,5 & 12 & 0,94 & 0,21 & 16 & 0,57 & 0,31 \\
\hline
\end{tabular}


Figura 6 - Faixas de variação das resistências de aderência à tração dos revestimentos

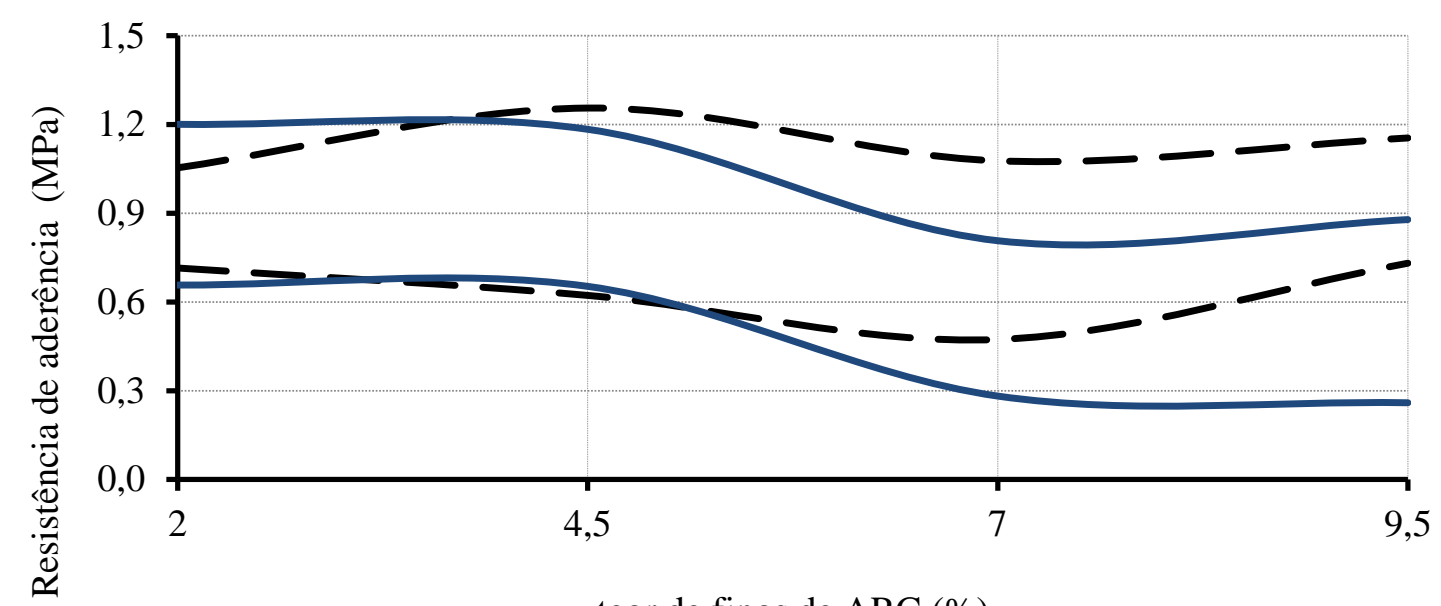

teor de finos de ARC (\%)

- - - antes do envelhecimento

O envelhecimento acelerado resultou em aumento no percentual de ruptura na argamassa e na interface argamassa/chapisco (Tabela 7). Constata-se que os revestimentos possuem boa aderência na interface chapisco/substrato, por apresentarem baixos percentuais de ruptura nessa interface ou no substrato.

Nas Figuras 7 e 8 são visualizados simultaneamente os valores médios de resistência de aderência e de forma de ruptura observados nos diversos revestimentos, antes e depois do envelhecimento acelerado.

Embora as resistências de aderência dos revestimentos não submetidos ao envelhecimento acelerado e com diferentes teores de adição de finos expressem resultados próximos, sua forma de ruptura é distinta. No revestimento com $2 \%$ de finos há $24 \%$ de rupturas no substrato e na interface argamassa/chapisco, o que indica que essa argamassa é a que apresenta a melhor condição de aderência dentre as ensaiadas. Ao se aumentar o teor de adição de finos, há uma contínua diminuição desse tipo de ruptura, enquanto o percentual de rupturas na argamassa ou na interface argamassa/chapisco aumenta.

Por meio da Figura 8, verifica-se que em todos os revestimentos ocorre uma sensível diferença na forma de ruptura, que após a ciclagem térmica passa a ocorrer quase totalmente na argamassa e na interface argamassa/chapisco. Há maior degradação
--- depois do envelhecimento acelerado

dos revestimentos produzidos com os dois menores teores de adição (2\% e 4,5\%). Nessas argamassas ocorre uma diferença expressiva na forma de ruptura: essas argamassas, que apresentavam uma relação na ordem de 1 : 1 entre as rupturas na argamassa e no chapisco e substrato, passam a apresentar cerca de $70 \%$ de rupturas na argamassa, e mais de 95\% das rupturas entre a argamassa e a interface argamassa/chapisco. Nos revestimentos com maior teor de adição, há um comportamento distinto, verificando-se equilíbrio entre as formas de ruptura "argamassa" e "interface argamassa/chapisco”. Após a ciclagem térmica, a argamassa com o teor de $7 \%$ de finos apresentou diminuição na área de substrato aparente (de 4\% para praticamente zero) e na área de ruptura no chapisco (de 65\% para 45\%), o que configura perda de aderência na interface argamassa/chapisco. Zeng et al. (2012) também observaram menor degradação com o aumento da porosidade (o que ocorre nas argamassas com 7\% e 9,5\% de finos), em função de o CET diminuir em argamassas mais porosas. As argamassas com maior teor de finos apresentaram maior índice de vazios e menor densidade (Tabela 4), que podem ter diminuído a restrição à deformação decorrente dos ciclos de aquecimento e/ou resfriamento no interior do revestimento, gerando menores tensões internas durante a movimentação resultante da variação de temperatura e consequentemente menor degradação desses revestimentos. 
Tabela 7 - Médias das resistências de aderência à tração e percentuais médios de incidência de cada forma de ruptura, considerando-se todos os revestimentos avaliados

\begin{tabular}{l|c|c|c|c|c}
\hline & \multirow{2}{*}{$\begin{array}{c}\text { Resistência } \\
\text { Tipo de } \\
\text { exposição } \\
\text { aderência } \\
\text { à tração } \\
\text { (MPa) }\end{array}$} & Argamassa & $\begin{array}{c}\text { Forma de ruptura (\%) } \\
\text { Interface } \\
\text { Argamassa/chapisco }\end{array}$ & $\begin{array}{c}\text { Interface } \\
\text { Chapisco/substrato }\end{array}$ & Substrato \\
\hline $\begin{array}{l}\text { Antes do } \\
\text { envelhecimento } \\
\text { acelerado }\end{array}$ & 0,83 & 46,72 & 42,44 & 10,23 & 0,60 \\
\hline $\begin{array}{l}\text { Após } \\
\text { envelhecimento } \\
\text { acelerado }\end{array}$ & 0,70 & 58,03 & 37,40 & 4,43 & 0,14 \\
\hline
\end{tabular}

Figura 7 - Resistência de aderência à tração (RA) e percentuais de ocorrência de cada forma de ruptura dos revestimentos antes do envelhecimento acelerado

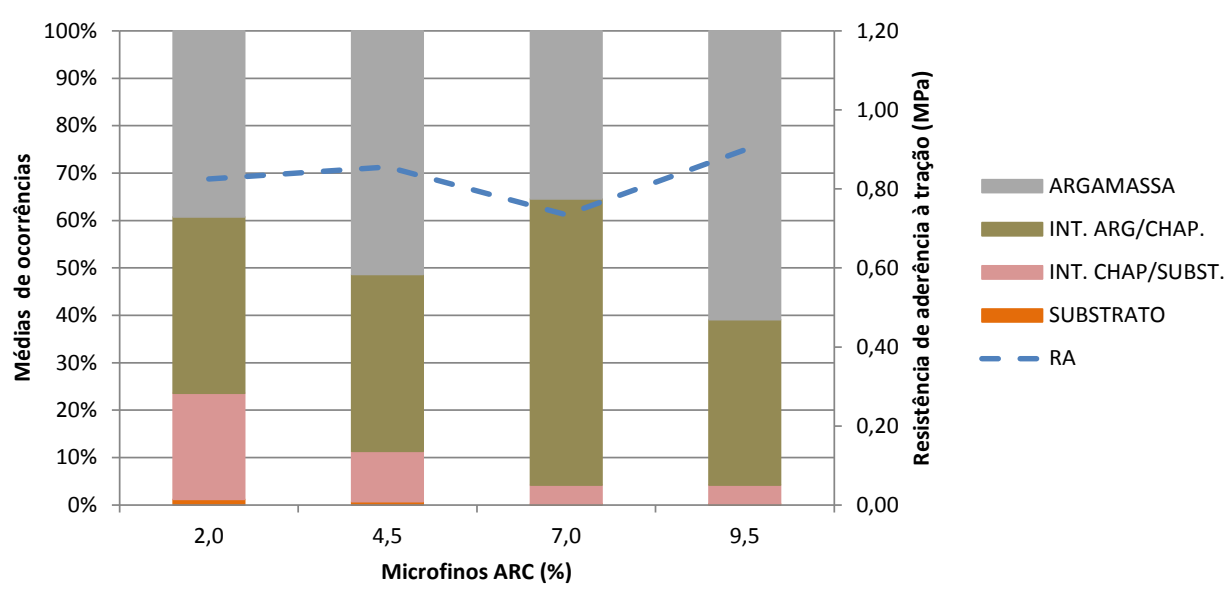

Figura 8 - Resistência de aderência à tração e percentuais de ocorrência de cada forma de ruptura dos revestimentos depois do envelhecimento acelerado

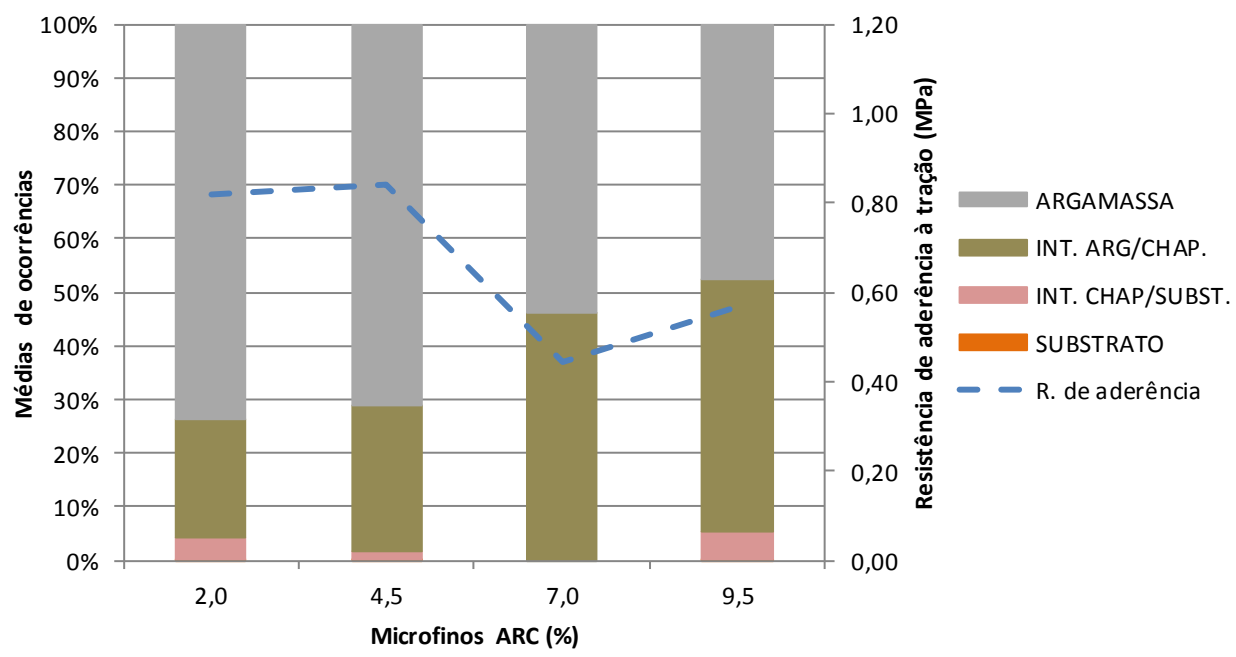




\section{Conclusão}

A exposição dos revestimentos de argamassa com finos provenientes da moagem de concreto a ciclos de envelhecimento acelerado por ciclagem de temperatura e choque térmico resultou em alterações em suas propriedades, constatadas por todos os métodos de avaliação utilizados.

Em função da exposição ao ensaio de envelhecimento acelerado, ocorreu diminuição da velocidade de propagação de ondas ultrassônicas na ordem de 25\%, decorrente do aumento na quantidade de vazios, e diminuição da dureza superficial na ordem de $10 \%$. Nesses ensaios, entretanto, não foi possível distinguir diferenças de comportamento entre as argamassas com diferentes teores de adição de finos.

A resistência de aderência dos revestimentos, aos 28 dias de idade, diminuiu proporcionalmente ao aumento do teor de finos de concreto. Após o envelhecimento acelerado, apresentou uma queda média na ordem de $15 \%$, mas como o ensaio apresentou elevada variabilidade, também não permitiu a distinção da aderência entre os revestimentos com diferentes teores de adição de finos. Entretanto, a partir da análise da forma de arrancamento, foi possível constatar maior degradação nos revestimentos produzidos com os dois menores teores de finos (2\% e $4,5 \%)$. Nessas argamassas foi constatada uma diferença expressiva na forma de ruptura, com aumento de 50\% de área de ruptura na argamassa antes do envelhecimento acelerado para $70 \%$ após, e de $50 \%$ de área de rupturas na argamassa e na interface argamassa/chapisco para mais de 95\% após o ensaio. Nos revestimentos com maior teor de adição de finos, houve um comportamento distinto, verificando-se equilíbrio entre as formas de ruptura “argamassa” e “interface argamassa/chapisco”. A argamassa com o teor de $7 \%$ de finos apresentou diminuição na área de substrato aparente (de 4\% para praticamente zero) e na área de ruptura no chapisco (de 65\% para 45\%), o que configura perda de aderência na interface argamassa/chapisco.

\section{Referências}

AMERICAN SOCIETY FOR TESTING AND MATERIALS. D 2240-05: standard test method for rubber property: durometer hardness. Philadelphia, 2005.

\section{ASSOCIAÇÃO BRASILEIRA DE NORMAS}

TÉCNICAS. NBR 13279: argamassa para assentamento e revestimento de paredes e tetos: determinação da resistência à tração na flexão e à compressão. Rio de Janeiro, 2005a.
ASSOCIAÇÃO BRASILEIRA DE NORMAS

TÉCNICAS. NBR 13280: argamassa para assentamento e revestimento de paredes e tetos: determinação da densidade de massa aparente no estado endurecido. Rio de Janeiro, 2005b.

\section{ASSOCIAÇÃO BRASILEIRA DE NORMAS} TÉCNICAS. NBR 13528: revestimento de paredes e tetos de argamassas inorgânicas: determinação da resistência de aderência à tração. Rio de Janeiro, 2010.

\section{ASSOCIAÇÃO BRASILEIRA DE NORMAS}

TÉCNICAS. NBR 15259: argamassa para assentamento e revestimento de paredes e tetos: determinação da absorção de água e do coeficiente de capilaridade. Rio de Janeiro, 2005d.

\section{ASSOCIAÇÃO BRASILEIRA DE NORMAS TÉCNICAS. NBR 15575-4: edificações} habitacionais: desempenho: parte 4: requisitos para os sistemas de vedações verticais internas e externas: SVVIE. Rio de Janeiro, 2013.

\section{ASSOCIAÇÃO BRASILEIRA DE NORMAS TÉCNICAS. NBR 15630: argamassa para} assentamento e revestimento de paredes e tetos: determinação do módulo de elasticidade dinâmico através da propagação de onda ultrassônica. Rio de Janeiro, 2009.

\section{ASSOCIAÇÃO BRASILEIRA DE NORMAS TÉCNICAS. NBR 9778: argamassa e concreto endurecidos: determinação da absorção de água, índice de vazios e massa específica. Rio de Janeiro, 2005c.}

\section{ASSOCIAÇÃO BRASILEIRA DE NORMAS} TÉCNICAS. NBR NM 23: cimento Portland e outros materiais em pó: determinação da massa específica. Rio de Janeiro, 2000.

\section{ASSOCIAÇÃO BRASILEIRA DE NORMAS TÉCNICAS. NBR NM 45: agregados:} determinação da densidade de massa e do volume de vazios. Rio de Janeiro, 2006.

BALLESTER, P. et al. Effect of Brief HeatCuring on Microstructure and Mechanical Properties in Fresh Cement Based Mortars. Cement and Concrete Research, v. 39, n. 7. p. 573-579, Jul. 2009.

CARASEK, H. Avaliação de Resultados do Ensaio de Resistência de Aderência de Revestimentos de Argamassa. Téchne, v. 20, n. 185, jun. 2012.

CARÉ, S. Effect of Temperature on Porosity and on Chloride Diffusion in Cement Pastes.

Construction and Building Materials, v. 22, n. 07, p. 1560-1573, Jul. 2008. 
ESQUIVEL, J. T. Avaliação da Influência do Choque Térmico na Aderência dos Revestimentos de Argamassa. 262 f. São Paulo, 2009. Tese (Doutorado em Engenharia) - Escola Politécnica, Universidade de São Paulo, São Paulo, 2009.

FREITAS, V. P. et al. Discussing the Durability Assessment of Cement Mortars: a contribution for a prediction model. In: INTERNATIONAL CONFERENCE ON DURABILITY OF BUILDING MATERIALS AND COMPONENTS, Istanbul, 2008. Anais... Istanbul, 2008.

GHABEZLOO, S. Micromechanics Analysis of Thermal Expansion and Thermal Pressurization of a Hardened Cement Paste. Cement and Concrete Research, v. 41, n. 5, p. 520-532, May 2011.

GOMES, M. G. et al. The Influence of Moisture Content on the Thermal Conductivity of External Thermal Mortars. Construction and Building Materials, v. 135, p. 279-286, jan. 2017.

GUIMARÃES, L. E. et al. Acompanhamento das Variações das Temperaturas Superficiais dos Principais Materiais Utilizados em Fachadas. In: ENCONTRO SOBRE PESQUISAS DE MATERIAIS DE CONSTRUÇÃO, 2., Goiânia, 2002. Anais... Goiânia, 2002.

INSTITUTO DE PESQUISAS

TECNOLÓGICAS. Critérios Mínimos de Desempenho Para Habitações de Interesse Social. São Paulo: IPT, 1998.

JANOTKA, I.; NÜRNBERGEROVÁ, T. Effect of Temperature on Structural Quality of the Cement Paste and High-Strength Concrete With Silica Fume. Nuclear Engineering and Design, v. 235, n. 17-19, p. 2019-2032, Aug. 2005.

KIM, K. et al. An Experimental Study on Thermal Conductivity of Concrete. Cement and Concrete Research, v. 33, n. 3, p. 363-371, Mar. 2003.

LINO, G. A. L. Caracterização in situ de Rebocos Com Base em Cal e Metacaulino Aplicados em Muretes Experimentais.125 f. Lisboa, 2013. Dissertação (Mestrado em Engenharia Civil) - Faculdade de Ciências e Tecnologia, Universidade Nova de Lisboa, Lisboa, 2013.
MEYERS, S. L. Thermal Coefficient of Expansion of Portland Cement: long-timetests. Industrial and Engineering Chemistry, v. 32, n. 8, p. 11071112, Aug. 1940.

\section{MINISTÉRIO DE MINAS E ENERGIA.}

Relatório n ${ }^{\circ}$ 31: perfil de areia para construção civil. Disponível em:

$<$ http://www.mme.gov.br/web/guest/publicacoese-indicadores>. Acesso em: 22 dez. 2016.

MIRANDA, L. F. R.; SELMO, S. M. S. CDW Recycled Aggregate Renderings: part II: analysis of the effect of materials finer than $75 \mu \mathrm{m}$ under accelerated aging performance. Construction and Building Materials, v. 20, p. 625-633, Jun. 2005.

MURUYAMA, I.; TERAMOTO, A.; IGARASHI, G. Strain and Termal Expansion Coefficients of Various Cement Pastes During Hydration at Early Ages. Materials and Structures, v.47, p. 27-37, Jan. 2014.

SARAIVA, A. G.; BAUER, E.; BEZERRA, L. M. Análise das Tensões Entre Argamassa Colante e Placas Cerâmicas Submetidas a Esforços de Natureza Térmica. Brasília: Universidade de Brasília, 2011.

SCHULSON, E. M.; SWAINSON, I. P.; HOLDEN, T. M. Internal Stress Within Hardened Cement Paste Induced Through Thermal Mismatch: calcium hydroxide versus calcium silicate hydrate. Cement and Concrete Research, v. 31, n. 12, p. 1785-1791, Dec. 2001.

SHUI, Z. et al. Effects of Mineral Admixtures on the Thermal Expansion Properties of Hardened Cement Paste. Construction and Building Materials, v. 24, n. 9, p. 1761-1767, Sep. 2010.

SOLTANI, F. et al. Relationship Between Ultrasonic Rayleigh Wave Propagation and Capillary Porosity in Cement Paste With Variable Water Content. NDT\&E International, v. 54, p. 75-83, Mar. 2013.

ZENG, Q. et al. Effect of Porosity on Thermal Expansion Coefficient of Cement Pastes and Mortars. Construction and Building Materials, v. 28, n. 1, p. 468-475, Mar. 2012.

\section{Agradecimentos}

Os autores agradecem à FINEP, FAPERGS e CNPq pelo auxílio financeiro para o desenvolvimento deste trabalho. 


\section{J eferson Alcântara Alves Sentena}

Programa de Pós-Graduação em Engenharia Civil | Universidade do Vale do Rio dos Sinos | Av. Unisinos, 950, Cristo Rei | São Leopoldo RS - Brasil | Caixa Postal 275 | CEP 93022-750 | Tel.: (51) 3590-8245 | E-mail: jefersonsentena@gmail.com

\section{Claudio de Souza Kazmierczak}

Programa de Pós-Graduação em Engenharia Civil | Universidade do Vale do Rio dos Sinos | E-mail: claudiok@unisinos.br

\section{Laércio Antônio Krein}

Curso de Graduação em Engenharia Civil | Universidade do Vale do Rio dos Sinos | E-mail: laercio70@hotmail.com

\section{Revista Ambiente Construído}

Associação Nacional de Tecnologia do Ambiente Construído

Av. Osvaldo Aranha, 99 - 30 andar, Centro

Porto Alegre - RS - Brasil

CEP 90035-190

Telefone: +55 (51) 3308-4084

Fax: +55 (51) 3308-4054

www. seer. ufrgs. br/ ambienteconstruido

E-mail: ambienteconstruido@ufrgs.br 